\title{
ON AN EXAMPLE IN SECOND ORDER LINEAR ORDINARY DIFFERENTIAL EQUATIONS
}

\section{WILLETT}

Let $b(t)$ be a given positive nondecreasing continuous function on the set $t \geqq 0$. In this note we will prove the following result:

THEOREM. There exists a positive continuously differentiable function $a(t)$ such that $a^{\prime}(t) \geqq b(t)$ and the differential equation

$$
x^{\prime \prime}+a(t) x=0 \quad t \geqq 0 \quad\left(\prime=\frac{d}{d t}\right),
$$

has at least one solution $x=x(t)$ such that

$$
\limsup _{t \rightarrow \infty}|x(t)|>0 \text {. }
$$

The above theorem generalizes the examples given by Milloux [4], Hartman [3], and Galbraith, McShane, and Parrish [2], whose methods do not necessarily produce a function $a(t)$ with $a^{\prime}(t) \geqq b(t)$, if $b(t)$ is taken of sufficiently large order as $t \rightarrow \infty$. Such examples are of interest in regard to the converse problem, i.e., what conditions besides $a(t) \uparrow \infty$ as $t \uparrow \infty$ need to be assumed in order to know that all solutions of (1) satisfy $x(t) \rightarrow 0$ as $t \rightarrow \infty$. The book by Cesari [1, pp. 84-86] has a good discussion of this problem. Willett, Wong, and Meir [5] list some new results in this direction. We take the occasion to point out that in $[1$, p. 86] Sansone's sufficient condition there reported should read, "If $a(t)$ is positive, nondecreasing, with a continuous derivative in $\left[t_{0},+\infty\right]$, if $a^{\prime}(t) \rightarrow \infty$, and $\int^{+\infty} a^{-1}(t) d t=\infty$, then for every solution $x(t)$ of (1) we have $x(t) \rightarrow 0$ as $t \rightarrow+\infty$." This corrects a misprint in $[1$, p. 86] (where " $=+\infty "$ was printed as " $<\infty$ ").

In order to prove our main theorem, we will need the simple properties of solutions to (1) stated in the following lemma.

Lemma. Let $x(t)$ be any solution of (1) for a given continuous $a(t)$, and let $\mu$ and $T$ be positive numbers such that $a(t) \geqq \mu^{2}$ for all $t$ in $[0, T]$. Then $x^{\prime}$ has finitely many zeroes in $[0, T]$, and if $t_{0}<t_{1}<\cdots<t_{n}$ are those zeroes then $0<t_{k}-t_{k-1} \leqq 2 \pi \mu^{-1}(k=1,2, \cdots, n)$.

Proof. By the Sturm Comparison Theorem, for any solution $x(t)$ 1966.

Presented to the Society, December 2, 1965; received by the editors January 3, 
of (1), $x(t)$ has a finite number of zeroes in the interval $0 \leqq t \leqq T$. If $\tau_{1}$ and $\tau_{2}$ are successive zeroes, then $\tau_{2}-\tau_{1} \leqq \pi \mu^{-1}$. Now between $\tau_{1}$ and $\tau_{2}, x(t)$ is either always positive or always negative. Hence, since $x^{\prime \prime}(t)=-a(t) x(t), x$ is either strictly concave or strictly convex for $\tau_{1} \leqq t \leqq \tau_{2}$, and so $x$ has exactly one critical point between $\tau_{1}$ and $\tau_{2}$. Clearly the lemma follows.

Proof of The Theorem. Let

$$
a_{1}(t)=4 \pi^{2}+\int_{0}^{t} b(s) d s
$$

for $t$ in $\left[0, t_{1}\right]$, where $t_{1}$ is such that $\frac{1}{2} \leqq t_{1} \leqq 1$ and $x_{1}^{\prime}\left(t_{1}\right)=0$ for $x_{1}(t)$ the unique solution to

$$
x_{1}^{\prime \prime}+a_{1}(t) x_{1}=0, \quad x_{1}(0)=x_{0}>0, \quad x_{1}^{\prime}(0)=0 .
$$

By the lemma, such a point $t_{1}$ must exist. For $t>t_{1}$ define $a_{1}(t)=x_{1}(t)$ $=0$. Finally, let $0<\epsilon_{n}<1$ be a given sequence of numbers such that $x_{1}^{2}\left(t_{1}\right) \geqq\left(1-\epsilon_{1}\right) x_{0}^{2}$ and $\sum_{n=1}^{\infty} \epsilon_{n}<\infty$.

The proof of the theorem is inductive in nature. Suppose that a set of numbers $0=t_{0}<t_{1}<\cdots<t_{n-1}$ such that

$$
\frac{1}{2} \leqq t_{k}-t_{k-1} \leqq 1 \quad(k=1,2, \cdots, n-1)
$$

and a set of functions $a_{k}(t), x_{k}(t)(k=1,2, \cdots, n-1)$ have been determined so that the following holds $(k=1,2, \cdots, n-1)$ :

$$
\begin{aligned}
& x_{k}^{\prime \prime}+a_{k}(t) x_{k}=0 \quad \text { and } \quad a_{k}^{\prime}(t) \geqq b(t) \quad \text { for } \quad t \in\left[t_{k-1}, t_{k}\right], \\
& x_{k}(t)=a_{k}(t)=0 \quad \text { for } \quad t \in\left[t_{k-1}, t_{k}\right], \\
& x_{k}\left(t_{k-1}\right)=x_{k-1}\left(t_{k-1}\right), \quad x_{k}^{\prime}\left(t_{k-1}\right)=x_{k}^{\prime}\left(t_{k}\right)=0, \\
& a_{k}\left(t_{k-1}\right)=a_{k-1}\left(t_{k-1}\right), \quad a_{k}^{\prime}\left(t_{k-1}\right)=b\left(t_{k-1}\right), \quad a_{k}^{\prime}\left(t_{k}\right)=b\left(t_{k}\right) .
\end{aligned}
$$

Suppose also that

$$
x_{k}^{2}\left(t_{k}\right) \geqq\left(1-\epsilon_{k}\right) x_{k}^{2}\left(t_{k-1}\right) \quad(k=1,2, \cdots, n-1) .
$$

If we can obtain by induction a sequence of points $\left\{t_{k}\right\}$ and functions $\left\{a_{k}(t)\right\}$ and $\left\{x_{k}(t)\right\}$ satisfying (3), (4), and (5), the theorem will follow by taking

$$
a(t)=\sum_{k=1}^{\infty} a_{k}(t) \quad \text { and } \quad x(t)=\sum_{k=1}^{\infty} x_{k}(t) .
$$

From (5) we obtain

$$
x^{2}\left(t_{k}\right) \geqq\left(1-\epsilon_{k}\right) x^{2}\left(t_{k-1}\right) \geqq \prod_{j=1}^{k}\left(1-\epsilon_{j}\right) x_{0}^{2} \quad(k=1,2, \cdots) .
$$


Since $t_{k} \rightarrow \infty$ as $k \rightarrow \infty$ and $\sum_{j=1}^{\infty} \epsilon_{j}<\infty$,

$$
\limsup _{t \rightarrow \infty} x^{2}(t) \geqq \prod_{j=1}^{\infty}\left(1-\epsilon_{j}\right) x_{0}^{2}>0 .
$$

Thus, we have to show the existence of a point $t_{n}$ and functions $a_{n}(t)$ and $x_{n}(t)$ such that (3), (4), and (5) hold with $k=n$. Let $\alpha$ be any positive number satisfying $\alpha>a_{n-1}\left(t_{n-1}\right)+b\left(1+t_{n-1}\right)$ and $\alpha>\left(\epsilon_{n}^{-1}-1\right) b\left(1+t_{n-1}\right)$. For $\alpha$ fixed, let $s_{n}$ be any number satisfying $0<s_{n}-t_{n-1}<\frac{1}{2}$ and

(6) $s_{n}-t_{n-1}<\left\{\frac{2}{\alpha}\left[1-\left(1-\epsilon_{n}\right)^{1 / 2}\left(1+\alpha^{-1} b\left(1+t_{n-1}\right)\right)^{1 / 2}\right]\right\}^{1 / 2}$.

Finally, let

$$
\begin{aligned}
a_{n}(t)= & \int_{t_{n-1}}^{t} b(\tau) d \tau+\frac{1}{2}\left(\alpha-\int_{t_{n-1}}^{s_{n}} b(\tau) d \tau\right)\left(1-\cos \pi \frac{t-t_{n-1}}{s_{n}-t_{n-1}}\right) \\
& +\frac{1}{2} a_{n-1}\left(t_{n-1}\right)\left(1+\cos \pi \frac{t-t_{n-1}}{s_{n}-t_{n-1}}\right)
\end{aligned}
$$

for $t_{n-1} \leqq t \leqq s_{n}$, and let

$$
a_{n}(t)=\alpha+\int_{s_{n}}^{t} b(\tau) d \tau
$$

for $s_{n} \leqq t \leqq t_{n}$. Here, $t_{n}$ is any point such that $\frac{1}{2} \leqq t_{n}-t_{n-1} \leqq 1$ and $x_{n}^{\prime}\left(t_{n}\right)=0$ for $x_{n}(t)$ defined on $\left[t_{n-1}, t_{n}\right]$ to be the solution of

$$
x_{n}^{\prime \prime}+a_{n}(t) x_{n}=0, \quad x_{n}\left(t_{n-1}\right)=x_{n-1}\left(t_{n-1}\right), \quad x_{n}^{\prime}\left(t_{n-1}\right)=0 .
$$

By the lemma, such a point $t_{n}$ must exist. Let $x_{n}(t)=a_{n}(t)=0$ for $t$ not in $\left[t_{n-1}, t_{n}\right]$. It is easy to verify that $a_{n}(t)$ is a continuously differentiable function on $\left[t_{n-1}, t_{n}\right]$, and that $a_{n}(t)$ and $x_{n}(t)$ satisfy (4) with $k=n$.

We will now prove that $x_{n}(t)$ satisfies (5) with $k=n$. For the sake of brevity in what follows, let $x=x_{n}$ and $a=a_{n}$. Since $x^{\prime}\left(t_{n-1}\right)=0$, by Taylor's Theorem we obtain

$$
x\left(s_{n}\right)-x\left(t_{n-1}\right)=\frac{1}{2}\left(s_{n}-t_{n-1}\right)^{2} x^{\prime \prime}(c) \quad\left(t_{n-1}<c<s_{n}\right) .
$$

Because $a^{\prime} \geqq 0$, the set of maxima of $|x(t)|$ are decreasing; hence

$$
\left|x^{\prime \prime}(c)\right|=a(c)|x(c)| \leqq a\left(s_{n}\right)\left|x\left(t_{n-1}\right)\right| .
$$

So

$$
\left|x\left(s_{n}\right)\right| \geqq\left[1-\frac{1}{2}\left(s_{n}-t_{n-1}\right)^{2} a\left(s_{n}\right)\right]\left|x\left(t_{n-1}\right)\right| .
$$


In order to estimate $\left|x\left(t_{n}\right)\right|$, we integrate $x^{\prime} x^{\prime \prime}+a x x^{\prime}=0$ by parts to obtain

$$
a\left(t_{n}\right) x^{2}\left(t_{n}\right)=\left[x^{\prime}\left(s_{n}\right)\right]^{2}+a\left(s_{n}\right) x^{2}\left(s_{n}\right)+\int_{s_{n}}^{t_{n}} a^{\prime}(t)[x(t)]^{2} d t
$$

Hence

$$
x^{2}\left(t_{n}\right) \geqq \frac{a\left(s_{n}\right)}{a\left(t_{n}\right)} x^{2}\left(s_{n}\right) \geqq \frac{x^{2}\left(s_{n}\right)}{1+\alpha^{-1} b\left(1+t_{n-1}\right)},
$$

since $a\left(s_{n}\right)=\alpha$ and

$$
a\left(t_{n}\right)-\alpha=\int_{s_{n}}^{t_{n}} b(t) d t \leqq b\left(t_{n}\right)\left(t_{n}-s_{n}\right) \leqq b\left(1+t_{n-1}\right) .
$$

Combining (7) and (8), we obtain

$$
x^{2}\left(t_{n}\right) \geqq \frac{\left[1-\frac{1}{2}\left(s_{n}-t_{n-1}\right)^{2} \alpha\right]^{2}}{1+\alpha^{-1} b\left(1+t_{n-1}\right)} x^{2}\left(t_{n-1}\right) .
$$

But from (6) it follows that

$$
\frac{\left[1-\frac{1}{2}\left(s_{n}-t_{n-1}\right)^{2} \alpha\right]^{2}}{1+\alpha^{-1} b\left(1+t_{n-1}\right)}>1-\epsilon_{n} .
$$

Hence, $x^{2}\left(t_{n}\right) \geqq\left(1-\epsilon_{n}\right) x^{2}\left(t_{n-1}\right)$, and the theorem follows.

\section{REFERENCES}

1. L. Cesari, Asymptotic behaviour and stability problems in ordinary differential equations, 2nd ed., Springer-Verlag, Berlin, 1963.

2. A. S. Galbraith, E. J. McShane, and G. B. Parrish, On the solutions of linear second-order differential equations, Proc. Nat. Acad. Sci. U.S.A. 53 (1965), 247-249.

3. P. Hartman, On a theorem of Milloux, Amer. J. Math. 70 (1948), 395-399.

4. H. Milloux, Sur l'équation différentielle $x^{\prime \prime}+A(t) x=0$, Prace Mat. 41 (1934), $39-53$.

5. D. Willett, J. S. W. Wong and A. Meir, On the asymptotic behaviour of solutions to certain second order linear ordinary differential equations, Michigan Math. J. (to appear).

University of Alberta, Canada 